\title{
Library Continuous Improvement through Collaboration on an Institution- Wide Assessment Initiative
}

\author{
Michael Luther and Jennifer Wells \\ Kennesaw State University, USA
}

\section{Introduction}

When assessment professionals in universities and academic libraries look past the methods and tools that they employ to the forces that motivate their work, they find three prime drivers. First is a motive for discovery. Opinions are held, behaviors are exhibited, and patterns exist within organizations that are unknown, yet we intuit that such knowledge would impact our decisions. Assessments of this type are commonly time- and resource-intensive, as the professional looks under many stones with the hope of gaining insight. The second driver is advocacy. Academic libraries compete for limited resources with other university departments. The university itself may compete for state funds against sister institutions. This competition engenders a motivation to advocate for stakeholder wants and needs and to gather compelling evidence to support them. The third and final driver is to demonstrate value. This motivation has become a dominant theme in the library assessment literature of recent years. ${ }^{1}$ It is related perhaps to the advocacy agenda, but it is also associated with demands for accountability. As providers of state- and university-level funds want assurances that these resources are being put to good use, so also do accreditation agencies seek to ensure quality educational experiences for students.

It is in this light-the motivation to demonstrate value-that Kennesaw State University (KSU) launched a continuous improvement plan (CIP) known as Improve KSU during the 2016-17 academic year. With a focus on student learning and performance outcomes, the library is an ideal connector between the two, "capable of crossing traditional boundaries between disciplinary programs and organizational units." 2 Having now completed the second full year of the cycle, assessment professionals within KSU's Office of Institutional Effectiveness (OIE) and the KSU Library System (KSULS) have their first opportunity to identify improvements for the articulated outcomes and to begin refining the CIP based on lessons learned.

\section{Literature Review}

The integration of continuous improvement into the culture and framework of an institution supports a desire for excellence and is one of the crossroads for higher education. The New Leadership Alliance for Student Learning and Accountability charges institutions of higher education to take responsibility for assessing and improving student learning and to ensure that students have developed the requisite skills to be successful and responsible citizens. ${ }^{3}$

Institutions of higher education must strive to continuously improve by employing integrated, institutionwide, research-based planning and evaluation processes that will ensure it is effectively accomplishing its mission. The vision, mission, and strategic plan serve as the blueprints for defining the fundamental criteria for assessing institutional effectiveness, which provides evidence for the achievement and success of an institution. An institution-wide approach to assessment requires that all faculty, staff, administrators, and students contribute to achieving continuous improvement and quality enhancement. Furthermore, units and programs must identify outcomes, assess the outcomes, relate those outcomes to the university mission, vision, and/or strategic plan, analyze the results of the assessments, and demonstrate improvements for those units and/or programs.

Assessment tells us the extent to which students have learned what we expect them to learn, how satisfied our internal/external customers are, how efficient or cost effective our processes are, and so on. This is further amplified by Kuh et al (2015): "assessment's purpose is to answer questions, shape better policies, make better decisions-all designed to improve student success and strengthen institutional performance." 4 
Over the last twenty years, much has been written about assessment and why it is important, but less has been written on how to implement assessment systems. ${ }^{5}$ Furthermore, there is agreement that one of the most challenging aspects of assessment is actually using results. "Doing assessment, simply performing assessment activities, is not the same as using assessment results." 7

In recent years, several articles have specifically addressed how to use results and how many institutions have not yet mastered that concept. ${ }^{8}$ In a study on use of results, only six percent of the institutions included evidence that student learning had improved. ${ }^{9}$ According to Kuh:

... most colleges and universities were using multiple measures to determine student learning outcomes. At the same time, relatively few schools were 'closing the loop,' or using the information in any material way to intentionally modify policy and practice. Rarer still were colleges or universities where changes in policies or practices made a positive difference in student attainment. ${ }^{10}$

The Principles of Good Practice in Assessing Learning outlines nine items that constitute quality and effective assessment practice. ${ }^{11}$ The Kennesaw State University (KSU) Improve KSU initiative addresses all of these in its approach. For example, "assessment is most effective when it reflects an understanding of learning as multidimensional, integrated, and revealed in performance over time" and "assessment is most likely to lead to improvement when it is part of a larger set of conditions that promote change." Kennesaw State has made an intentional effort to answer the call to create assessment processes that are focused on the use of results for continuous improvement.

\section{Methodology}

In 2015, Kennesaw State University and Southern Polytechnic State University consolidated to form a new university. This served as the impetus for the institution to recreate and redesign the campus-wide assessment process. An operational workgroup for institutional effectiveness comprised of respresentatives from across campus developed Improve KSU, a centralized, continuous improvement process for collecting student outcomes assessment information. The initiative has several goals:

- Build a culture of assessment and continuous improvement as a university

- Help drive our narrative as an institution

- Improve tracking of the strategic plan

- Compliance with accreditation standards

- Track assessment results and progress in a central location

In higher education and specifically at KSU, assessment focuses on specific expected outcomes pertaining to student learning and/or performance of administrative, operational, and student affairs units within the university. Student learning outcomes define expected knowledge, skills, attitudes, and competencies that students are expected to acquire. Performance outcomes are specific goals for an educational program or administrative, operational, or student affairs unit.

Figure 1 illustrates the process of KSU's university-wide, continuous improvement initiative, Improve KSU. 


\section{Figure 1: KSU's Continuous Improvement Model}

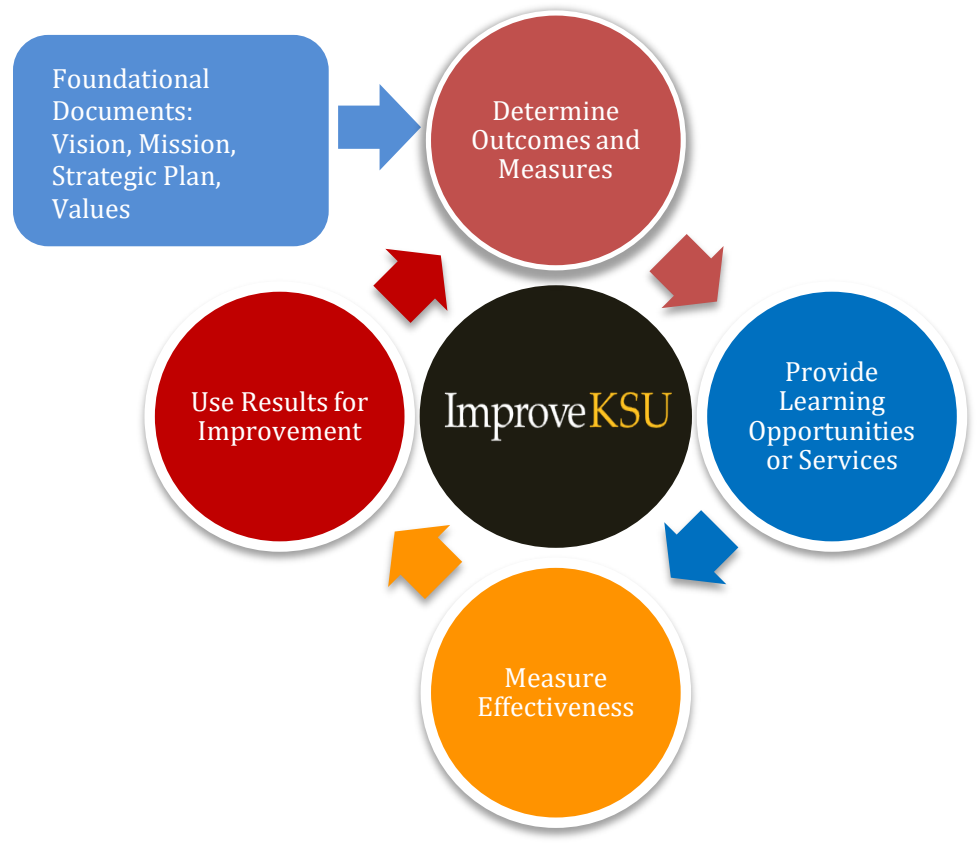

Units should first identify their purpose through foundational documents such as vision, mission, strategic plans, and values statements. From this, outcomes and measures should be identified that directly align with the foundational documents. Learning opportunities or services must then be provided so students have the opportunity to achieve the identified outcomes. Assessment methods are then employed to measure effectiveness. Finally, the results should be used for improvement and the assessment cycle continued.

Through Improve KSU, each educational program and administrative, operational, and student affairs unit is expected to document its assessment activities in annual "Assessment Plan and Improvement Reports" that are written by unit leaders and archived centrally by the Office of Institutional Effectiveness (OIE). These annual reports are expected to address the following key elements of KSU's institutional effectiveness process:

1. Identification of meaningful and measurable student outcomes (at least three for each academic and student services unit)

2. Identification of multiple measurement methods and data sources to determine the extent to which each outcome is achieved

3. Summarized measurement results of the extent to which each outcome was achieved

4. Analysis and interpretation of the measurement results that identify key assessment findings and opportunities for improvement of the service

5. Efforts underway to make specific improvements to the service as informed by assessment findings

6. Follow-up assessments that verify the effectiveness of past improvement initiatives and efforts and suggest additional avenues for continuing improvement

Rubrics are used to evaluate the strength of individual assessment plans and improvement reports. The rubrics provide a qualitative approach to generating constructive feedback that guides units to strengthen their outcomes, assessment measures, and strategies for improvement.

The University Assessment Council (UAC) oversees ongoing assessment to improve administrative, academic and student support services, educational programs, and student learning. The UAC fosters full participation in outcomes-based assessment. The UAC responsibilities include: 
- Propose and assist in the implementation of university institutional effectiveness (IE) policies and procedures

- Monitor the assessment of the KSU Strategic Plan

- Monitor the quality of program and unit assessment results, reports, and plans

- Provide an annual report to the president documenting strengths and weaknesses of the university's overall effort in assessment and institutional effectiveness

- Serve as a cross-campus forum for the exchange of ideas, information, and advice on methods and practices of assessment

- Keep the university community apprised of expectations for assessment, including expectations related to KSU's regional accreditation

- Work with those who engage in assessment activities to help them understand (or enhance) their activities

- Promote collaboration, optimizing the use of shared tools and resources among areas

\section{Findings}

\section{Macro-level}

The Office of Institutional Effectiveness (OIE) assessment team reviews the over 400 assessment plan and improvement reports and provides qualitative feedback using a rubric. One of the strategies the office uses for continuous improvement is to track the type of outcomes identified throughout campus. As previously mentioned, these are divided into learning and performance outcomes. Several outcome themes were developed by the assessment team and include: alumni; branding, visibility, and communication; partnerships and collaboration (internal or external); customer service; external funding through grants, contracts, or donations; productivity; process improvement or efficiency; usage and participation rates; user satisfaction; recruitment and enrollment; retention, progression, and graduation rates; research and creative activity or the scholarship of teaching and learning; professional development and training; constituent education; technology-enhanced learning; program quality and curriculum; and other. Each outcome is coded to one of the above themes. OIE is then able to develop a narrative for the institution regarding identified areas of improvement. Figure 2 shows the top six outcome areas identified in unit performance outcomes: retention, progression, and graduation (46\%); recruitment and enrollment (13\%); research and creative activity (11\%); high impact practices (11\%); program quality (10\%); and branding, visibility, and communication (9\%). The idea is that this type of information will then help inform campus-wide strategic initiatives, but also help show units how their work aligns amongst each other and the institution.

Figure 2: Top Six Outcome Areas Identified in Performance Outcomes (2016-2017)

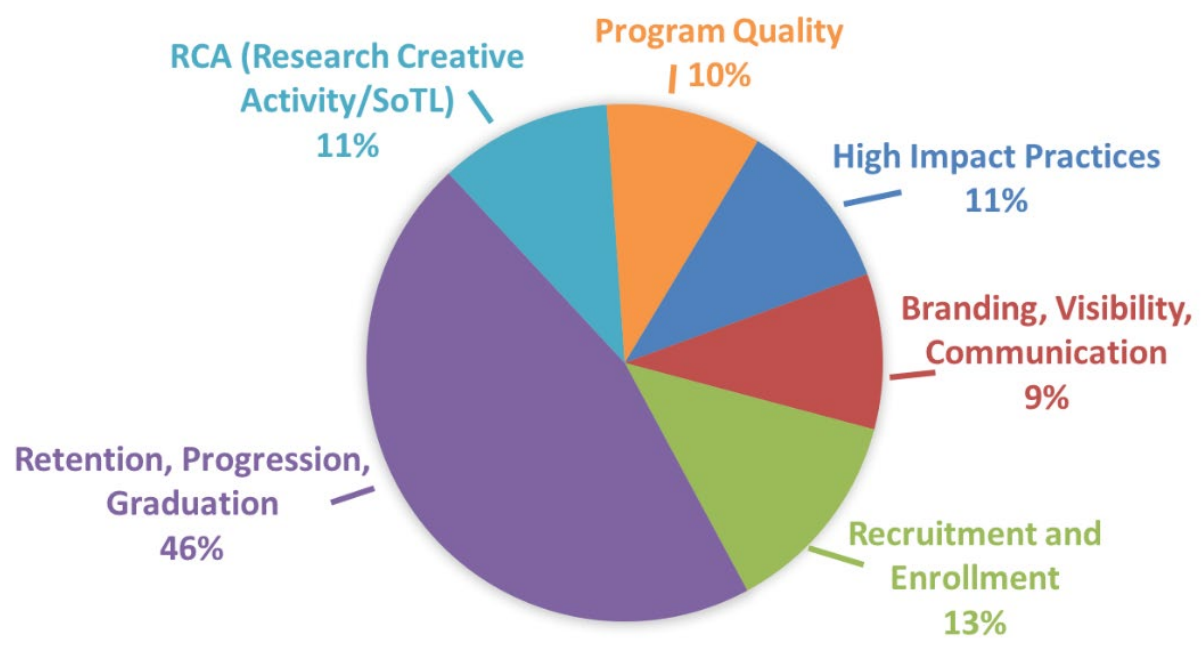


With over 400 units reporting outcomes, measures, results, trends, and areas of improvement, it would be difficult to list all of this information within this paper. To that end, the university has placed an emphasis on student success intitiatives. Strategies for improvement include increasing the number of students participating in high-impact practices, decreasing the number of students completing over 120 credit hours for graduation, increasing the number of students who complete 30 hours in the first year, and decreasing the number of students with undeclared majors. Ideally, the strategies that units implement for improvement should yield an overall improvement at the university level.

\section{Micro-Level}

With 24 outcomes distributed across the library system and its constituent units, it is not feasible to share all the findings within the limits of this paper. However, highlighting a few choice results should serve to illustrate the types of data that the KSU Library System is tracking and some of the issues that can arise.

Historically, the number of faculty and staff of the KSU Library System has failed to keep pace with the rapid enrollment growth of the university. In recent years, however, library administration has made a dedicated push to bring our personnel numbers more in line with our state peers. This is made especially challenging by the fact that our enrollment far exceeds those of our peers.

Table 1 illustrates the point. Despite a net gain of two library employees from FY 2017 to FY 2018, student headcount/library personnel actually slipped from 615.78 to 625.32 due to a significant enrollment increase over the same period. As of this writing, however, the KSU Library System has 63 employees. As such, the expectation is that next year's results will show a lot of improvement.

Table 1: Library System-level Result-Headcount/Library Personnel for KSU and 3 Georgia Comparators ${ }^{12}$

\begin{tabular}{|l|l|l|l|l|l|l|}
\hline & \multicolumn{2}{|l|}{ \# of Library Personnel } & \multicolumn{2}{l|}{$\begin{array}{l}\text { University Student } \\
\text { Headcount }\end{array}$} & \multicolumn{2}{l|}{$\begin{array}{l}\text { Headcount/Library } \\
\text { Personnel }\end{array}$} \\
\hline Year & FY 2017 & FY 2018 & FY 2017 & FY 2018 & FY 2017 & FY 2018 \\
\hline KSU & 54 & 56 & 33,252 & 35,018 & 615.78 & 625.32 \\
\hline GA Comp. \#1 & 57 & 57 & 20,459 & 20,418 & 358.93 & 358.21 \\
\hline GA Comp. \#2 & 40 & 37.1 & 12,834 & 13,308 & 320.85 & 358.32 \\
\hline GA Comp. \#3 & 40.3 & 39 & 11,302 & 11,375 & 280.45 & 291.67 \\
\hline
\end{tabular}

At the unit level, the Technical Services Unit defined an outcome with the goal of decreasing the length of time to receive and process print and electronic books. As KSULS strives to modernize its collection, processing efficiencies becomes critical. To this end, the Technical Services Unit randomly sampled shelfready, book firm orders, and eBook firm orders. Each sampled title received date stamps for selection date, order date, received date, and check-in date, allowing the unit to track the number of days from the initial selection of a title to its full discoverability within the catalog. Moreover, the multiple date stamps provide a level of detail necessary to document where efficiencies may have been made in the workflow, or where bottlenecks may exist. Table 2 compares these findings for the 2017 and the 2018 years of Improve KSU. 
Table 2: Library Unit-level Result-Processing Time (in days) for a Sample of Monographs by Order Type $^{13}$

\begin{tabular}{|l|l|l|l|l|}
\hline & \multicolumn{2}{|l|}{ Random Sample Size } & \multicolumn{2}{l|}{ Processing Time in Days } \\
\hline Year & 2017 & 2018 & 2017 & 2018 \\
\hline Shelf Ready Orders & 89 & 139 & 57.5 days & 43.5 days \\
\hline Book Firm Orders & 11 & 75 & 59.4 days & 78.6 days \\
\hline eBook Firm Orders & 50 & 77 & 17.6 days & 13.5 days \\
\hline
\end{tabular}

Table 2 documents significant improvements in processing time for both shelf-ready orders and eBook firm orders. However, the time to order, receive, and process book firm orders has increased. By looking at the detail (not provided), one sees that the delay is confined to the final segment of the workflow, the check-in process. Perhaps some known issue-for example, vacant positions or a change in leadership-accounts for the lag. Or, the apparent decrease in efficiency may be more of a mirage based on the comparatively small sample of orders in 2017. In any case, the consistent and methodical tracking of this data provides the director of technical services and other decision makers the essential business intelligence to take corrective action on this mission-critical work process.

One of the innovations for assessment as practiced at KSU is the intentional tying of decision-making to assessment results within the report template. This connection is made as the responsible individual (usually a library unit director) documents possible courses of action within the Brainstorming section of the template and then focuses in on a specific strategy or strategies within the Strategy for Improvement section of the template. The excerpts below document the director of library facilities' thinking and plan to increase library seating.

Brainstorming: To meet generally accepted seating guidelines for academic libraries that suggest a minimum of $10 \%$ of FTE, the Library System needs to add considerably more seats, particularly at the Sturgis Library. Short-term solutions focus on re-locating carrels from the Johnson Library to Sturgis, as the Marietta-based library acquires new furnishings. Inexpensive, flexible types of casual seating, such as beanbags, could be purchased. Longer-term strategies need to consider how we utilize new spaces for seating as the Academic Learning Center is built in the next several years. This will provide an opportunity for the Sturgis Library to expand services and functions on its fourth floor and into the Pilcher Building, and re-locate collections. Johnson Library also has potential opportunities to utilize new spaces for added seating capacity as nonlibrary departments such as CETL move out of the Johnson Library (C Building). ${ }^{14}$

Strategies for Improvement: Add approximately 50 carrels on areas of the Sturgis Library third floor where there is empty book shelving. These carrels are to be moved from the Johnson Library prior to installing new carrel furniture in the initial renovation phase in fall 2017. Another strategy to alleviate the strain on seating at the Sturgis Library will be flexible use of existing spaces. Classrooms and meeting spaces not in use can be made available for group and individual study during peak study periods and final exams. ${ }^{15}$

Narrations of this kind provide valuable context for library and university administrators as well as for accreditation agencies seeking to understand institutional value. It also serves as a repository of institutional memory, as library employees come and go, but the library's Continuous Improvement Plan continues on.

\section{Lessons Learned}

Following two years of Improve KSU, the authors have observed several factors that limit the effectiveness of outcome assessment and continuous improvement at the unit and library levels. 
First, while the institution follows the SMART acronym for outcomes (specific, measurable, achievable, relevant, and time-bound), the achievable part is often the most difficult. Many units want to set targets, which are often arbitrary, and continue to meet that target year after year. While that may be one goal, for the purposes of this initiative, it is about identifying areas of improvement. Once units have several years of data, they may find that they can set appropriate targets that support the continuous improvement mindset. In addition, it is not always clear from the outset if there is room for improvement on an outcome. For example, in the first year of the CIP, the library's Access Services Unit was interested in improving customer satisfaction at the main checkout desk. In a standard, fifteen-question survey administered to walk-up library patrons, participants were asked to rate their satisfaction with the helpfulness of library staff at the checkout desk. Out of 291 responses, $78.7 \%$ reported being very satisfied with checkout staff helpfulness, with another $14.4 \%$ reporting that they were satisfied. With $93 \%$ satisfaction, and only $1.4 \%$ claiming any degree of dissatisfaction, improving this outcome (at least as measured by this survey item) should no doubt prove difficult. Further, the survey item did include a "Not Applicable" response option for students who may have had no interaction with checkout staff. Indeed, when the question was asked again for the FY 2018 cycle of Improve KSU, $77.7 \%$ of respondents reported being very satisfied, $11.6 \%$ reported being satisfied, and only $0.9 \%$ reported a degree of dissatisfaction (328 responses).

A second main factor contributing to meaningful outcome assessment is the extent to which the outcome is patron-focused. In the first year of Improve KSU, the library system defined several outcomes relating to the training of faculty and staff. In year two, these were phased out in favor of more outward-facing outcomes. The trainings are better understood as interventions toward some larger goal, for example, a reduction in cataloging errors or higher rates of satisfaction at library service points. At the university level, the message is that outcomes should be meaningful and informative to the work. As demonstrated in the library example above, the outward-facing outcomes more often help to inform units in their quest for quality and improvement.

Finally, experience has taught that the most meaningful outcomes are mission critical. It is important to ask "what is the core mission of the unit defining the outcome (as shown in Fig. 1, the KSU Continuous Improvement Model)?" For a unit providing information literacy instruction, this might be evidence that students are learning new skills or, even better, applying them in their course work. These types of outcomes also provide evidence of impact and are more meaningful in nature. According to Gilchrist and Oakleaf, "academic librarians ...too, need to provide evidence of their value and direct contributions to student learning and success through well-designed outcomes assessment processes." 16

Any credible claim of improvement requires consistency both in the language of the outcome and in its measures. If this rule is held too strictly, of course, poorly worded outcomes and inexact measures would remain in perpetuity. The need for consistency, therefore, must be weighed against the need to define outcomes that are improvable, mission-critical, and patron-focused. To this end, the KSU Library System is revising forward, attempting to stay the course for at least two outcomes each cycle while substituting the weakest outcome for one that is more mission-critical and patron-focused.

The single largest change to the library's implementation of Improve KSU in the third year will be a move away from unit-based assessment and toward assessment of four strategic priorities: library resource management, library facilities, library services, and library organization (which, in essence, sits atop the other three). This makes sense because the work of libraries frequently requires collaboration of multiple units (think collection development and technical services), making it difficult to cleanly map an outcome to a single unit without involving others. Fortunately, most of the better outcomes from year two of the cycle map very cleanly to this new schema. Plus, there is a conservation of effort in that the library system will be defining and measuring 12 outcomes rather than 24 .

Improve KSU requires and encourages units, like the library, to outline their strategies for improvement. As shown in the example above, this can sometimes mean adjusting the assessment plan or even the outcomes so they can be more meaningful, informative, and manageable. As the institution and units mature in the 
assessment cycle, units will identify specific strategies for improvement in the learning opportunities and services provided.

Much like the units participating in Improve KSU, the initiative itself must follow a continuous improvement plan. The identified strategies are to first improve assessment synergy throughout the university to help reduce redundancy and increase the effectiveness of multiple assessment initiatives across the university. Second, units should place a greater focus on improvement and use of results. This was the area that needed the most improvement and so there will be more professional development and training opportunities focused on this part of the cycle. Finally, the online template, resource and educational materials, and feedback forms were all edited for clarity and ease of use by constituents.

\section{Conclusion}

Among the primary motivations of assessment work within universities and academic libraries is the compulsion to demonstrate value to a diverse group of stakeholders, including administrators, accreditation bodies, students, faculty, and the broader community. Specifically, the demonstrated improvement over time of well-crafted and consistently measured outcomes is an effective way of demonstrating value, especially when these outcomes are defined at various levels within the institution (unit/departmental/university). At each level, such outcome assessment encourages leadership to think deeply about what value it adds to the institution and how to most effectively demonstrate it. The process of continuous improvement is everchanging by definition, and the Improve KSU initiative represents the effort by Kennesaw State University to provide a high-quality and evolving experience for all involved.

-Copyright 2019 Michael Luther and Jennifer Wells

\section{Acknowledgements:}

The authors wish to thank Ms. Ariel Turner and Mr. Alan Lebish for permission to use examples of their work.

1. ACRL, Value of Academic Libraries.

2. Gilchrist and Oakleaf, "An Essential Partner,"16.

3. AAC\&U and CHEA, New Leadership.

4. Kuh et al., Using Evidence, 56.

5. Bresciani et al., Assessing Student Learning.

6. Blaich and Wise, "From Gathering to Using."

7. Kuh et al., Using Evidence, 56.

8. Baker et al., Using Assessment Results; Fulcher et al., "A Simple Model”; Fulcher, "Return of the Pig”;

Heinerichs et al., "Guiding Principles"; Walvoord, Assessment Clear and Simple.

9. Banta and Blaich, "Closing the Assessment Loop."

10. Kuh, forward to "From Gathering to Using," 4.

11. Astin et al., "Principles of Good Practice."

12. "USG Comparators."

13. Ariel Turner, Data submitted within Improve KSU, September 30, 2018

14. Alan Lebish, Text submitted within Improve KSU, September 30, 2018

15. Alan Lebish, Text submitted within Improve KSU, September 30, 2018

16. Gilchrist and Oakleaf, "An Essential Partner," 4. 
Bibliography

“USG Comparators: FTE Per Library Personnel, 2016-2017.” ACRL Metrics. Accessed January 20, 2019. https://www.acrlmetrics.com.

Assocation of American Colleges and Universities (AAC\&U) \& Council for Higher Education Accreditation (CHEA). New Leadership for Student Learning and Accountabiilty: A Statement of Principles, Commitment to Action. Washington, DC: Authors, 2008.

Association of College and Research Libraries. Value of Academic Libraries: A Comprehensive Research Review and Report. Prepared by Megan Oakleaf. Chicago: Association of College and Research Libraries, 2010. http://www.ala.org/acrl/sites/ala.org.acrl/files/content/issues/value/val_report.pdf.

Astin, Alexander W., Trudy W. Banta, K. Patricia Cross, Elaine El-Khawas, Peter T. Ewell, Pat Hutchings, Theodore J. Marchese, Kay M. McClenney, Marcia Mentkowski, Margaret A. Miller, et al. "Principles of Good Practice for Assessing Student Learning.” Leadership Abstracts 6, no. 4 (1993).

Baker, Gianina R., Natasha A. Jankowski, Staci Provezis, and Jillian Kinzie. Using Assessment Results: Promising Practices of Institutions That Do It Well. Urbana, IL: National Institute for Learning Outcomes Assessment (NILOA), 2012.

Banta, Trudy W. and Charles Blaich. "Closing the Assessment Loop." Change: The Magazine of Higher Learning 43, no. 1 (January/February 2011): 22-27.

Blaich, Charles and Kathleen Wise. "From Gathering to Using Assessment Results: Lessons from the Wabash National Study.” National Institute for Learning Outcomes Assessment Occassional Paper, no. 8 (January 2011): 1-19.

Bresciani, Marilee J., Carrie L. Zelna, and James A. Anderson. Assessing Student Learning and Development: A Handbook for Practitioners. Washington, DC: National Association of Student Personnel Administration, 2004.

Fulcher, K.H., Megan R. Good, Chris M. Coleman, and Kristen L. Smith. "A Simple Model for Learning Improvement: Weigh Pig, Feed Pig, Weigh Pig." National Institute for Learning Outcomes Assessment Occassional Paper no. 23 (December 2014): 1-19.

Fulcher, Keston H, Kristen L. Smith, Elizabeth R.H. Sanchez, Allison J. Ames, and Cara Meixner. "Return of the Pig: Standards for Learning Improvement." Research \& Practice in Assessment 11 (2017): 10-14.

Gilchrist, Debra and Megan Oakleaf. "An Essential Partner: The Librarian's Role in Student Learning Assessment.” National Institute for Learning Outcomes Assessment Occassional Paper no. 14 (April 2012): $1-24$.

Heinerichs, Scott, Lorraine R. Bernotsky, and Loretta Rieser Danner. "Guiding Principles to Impact an Institution-Wide Assessment Initiative.” Research \&t Practice in Assessment 10 (Summer 2015): 60-64.

Kuh, George D. Foreward to "From Gathering to Using Assessment Results: Lessons from the Wabash National Study.” By Charles Blaich and Kathleen Wise. NILOA Occasional Paper No. 8. Urbana, IL, 2011, 4.

Kuh, George D., Stanley O. Ikenberry, Natasha A. Jankowski, Timothy Reese Cain, Peter T. Ewell, Pat Hutchins, and Jillian Kinzie. Using Evidence of Student Learning. San Francisco, CA: Jossey-Bass, 2015.

Walvoord, Barbara E. Assessment Clear and Simple: A Practical Guide for Institutions, Departments, and General Education. San Francisco, CA: Jossey-Boss, 2010. 